\title{
Gradhiva
}

GRADHIV

Revue d'anthropologie et d'histoire des arts

18 | 2013

Le monde selon l'Unesco

\section{Comment parvenir à un consensus. De la Commission sur la culture et le développement à la Convention de 2003}

\author{
Lourdes Arizpe \\ Traducteur : Frédéric Eugène Illouz
}

\section{(2) OpenEdition Journals}

Édition électronique

URL : http://journals.openedition.org/gradhiva/2738

DOI : 10.4000/gradhiva.2738

ISSN : 1760-849X

Éditeur

Musée du quai Branly Jacques Chirac

\section{Édition imprimée}

Date de publication : 1 décembre 2013

Pagination : 146-165

ISBN : 978-2-35744-072-2

ISSN : 0764-8928

\section{Référence électronique}

Lourdes Arizpe, «Comment parvenir à un consensus. De la Commission sur la culture et le développement à la Convention de 2003 », Gradhiva [En ligne], 18 | 2013, mis en ligne le 01 décembre 2016, consulté le 19 avril 2019. URL : http://journals.openedition.org/gradhiva/2738; DOI : 10.4000/ gradhiva.2738

(c) musée du quai Branly 


\title{
Comment parvenir à un consensus
} De la Commission sur la culture et le développement à la Convention de $2003^{1}$

\author{
par Lourdes Arizpe
}

Le patrimoine culturel immatériel constitue une stratégie de la politique internationale concernant la culture et le développement qui débuta dans les années 1990. Depuis la Conférence intergouvermentale sur les politiques culturelles (Mondiacult) de 1982, les pays émergents insistaient pour que la culture soit prise en compte dans le développement «endogène"; ils réussirent à instaurer la Décennie 1987-1997 des Nations unies sur la culture et le développement ${ }^{2}$ et la Commission mondiale des Nations unies sur la culture et le développement (1992-1995). Je devins l'un des membres de la Commission en 1992, étant à l'époque présidente de l'Union internationale des sciences anthropologiques et ethnologiques. Peu après, dans le cadre de mes fonctions de directrice générale adjointe pour la culture à I'Unesco (1994-1998), puis dans les années suivantes comme conseillère (2000-2002), j'ai contribué à poser les bases de la Convention de 2003. Depuis 2004, mes recherches au Mexique se concentrent sur le patrimoine culturel immatériel. Les brèves remarques qui suivent se fondent sur mon expérience d'anthropologue dans la recherche et sur les débats, au niveau international, qui ont abouti à définir des instruments pour la culture ayant valeur normative dans les pays membres de l'Unesco.

En 1994, je fus invitée par le directeur général de l'Unesco, Federico Mayor, à occuper le poste de directrice générale adjointe pour la culture à I'Unesco. À mon étonnement, je m'aperçus que je devenais responsable de plus de trois cents projets sur la culture dans le monde entier. Emportée par plusieurs courants culturels et politiques, je dus évaluer en peu de temps des situations politiquement sensibles, comprendre les raisons des accords et des désaccords, contrer les opinions négatives au sujet du personnel de l'Unesco pour une meilleure compréhension des mécanismes sous-jacents de la géopolitique du pouvoir, ouvrir de nouveaux horizons intellectuels et de coopération internationale, et enfin, dans la mesure du possible, prendre des décisions afin de peser sur les programmes culturels internationaux.

Inutile de dire que mon expérience ethnographique s'est révélée extrêmement utile pour comprendre rapidement aussi bien les schémas culturels de pays et de régions différents que les structures profondes d'une organisation politiquement aussi complexe que l'Unesco. Cependant, ne me contentant pas d'être "expert témoin ", ainsi que se considèrent certains anthropologues travaillant dans des institutions internationales, je tenais à influencer les politiques culturelles mondiales. Je me suis alors retrouvée dans une situation me permettant de pousser plus loin l'«observation participante» pour devenir une «participante décisionnaire».
1. Certaines parties de cet article sont sous presse dans " Généalogie du concept de patrimoine culturel immatériel ", in Le Patrimoine culturel immatériel, Paris, Hermann ("Cerisy/Archives").

2. Voir Lourdes Arizpe, "The intellectual history of culture and development institutions ", in Robert Walton et Rao Vijendra (éd.), Culture and Public Action, Palo Alto, Stanford University Press, 2006. 


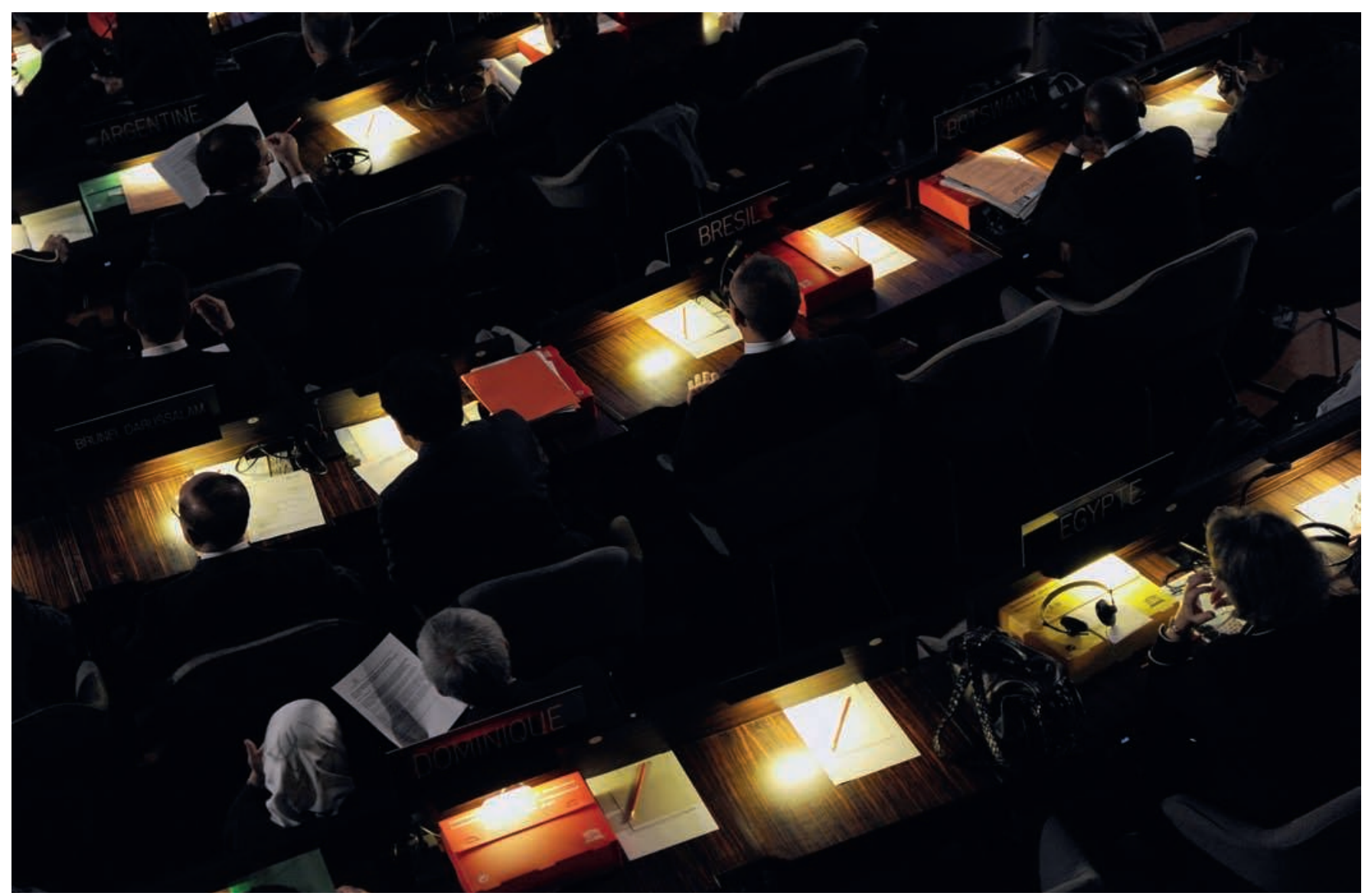

page précédente et ci-dessus

fig. 1

Siège de l'Unesco à Paris, bâtiment Fontenoy, Salle I. Des délégués permanents participent à la 35 ème Conférence générale de l'Unesco, 2009. (C) Michel Ravassard/Unesco.

\section{La Commission mondiale des Nations unies sur la culture et le développement et son rapport intitulé Notre diversité créatrice}

Après que la Conférence intergouvernementale de l'Unesco sur les politiques culturelles (Mondiacult), qui se tint à Mexico en 1982, eut élargi la définition de la culture en lui donnant une perspective plus anthropologique, le Groupe des 77, une organisation émanant des pays émergents, persuada l'Assemblée générale des Nations unies d'ouvrir une «Décennie 1987-1997 sur la culture et le développement ». Durant les premières années de la décennie, malgré le grand nombre d'événements culturels organisés dans différents pays, peu de progrès furent réalisés quant à la formulation d'un discours nouveau ayant une portée internationale sur la culture et le développement. En outre, des conflits internes menant à la guerre éclatèrent dans plusieurs pays, particulièrement dans l'ex-Yougoslavie, qui introduisirent les problématiques de la culture et de l'ethnicité sur la scène géopolitique internationale.

Javier Pérez de Cuéllar, ancien secrétaire général de l'ONU, l'expliquait ainsi: «Si après plusieurs décennies de développement certains des objectifs définis par la communauté internationale n'ont pas été atteints, c'est, entre autres raisons, parce que nous avons sous-estimé dans beaucoup de projets l'importance du facteur humain, ce réseau complexe de relations et de croyances, de valeurs et de motivations sous-jacent à chaque culture 
[...]. La culture, ou une autre forme de développement, parviendra-t-elle à élever des remparts contre la contagion de l'anti-culture propagée par la xénophobie et le nettoyage ethnique? »

Aussi, le 19 décembre 1991, l'Assemblée générale des Nations unies adopta une résolution visant à établir "une commission mondiale indépendante sur la culture et le développement» présidée par Pérez de Cuéllar. Il est intéressant de noter que l'Unesco, en tant qu'agence chargée de créer la commission et de l'assister, a rédigé une charte portant sur douze points: la relation entre culture et créativité, l'éducation, la communication, les industries culturelles, les modèles de développement, la science et la technologie, la population, l'universalité, les échanges culturels, la démocratie et les droits de l'homme ainsi que l'élaboration de stratégies, les rouages institutionnels, le plan d'action et les mécanismes permettant le financement et le suivi des opérations. Deux points essentiels avaient été laissés de côté; les commissaires insistèrent pour les y inclure: les femmes et l'environnement. Lors de la première réunion de la commission à Stockholm, les «directions d'enquête» furent réduites à sept et un chapitre fut dévolu au patrimoine culturel.

II n'y avait que deux anthropologues parmi les commissaires, Chie Nakane, éminente anthropologue japonaise, et moi-même ${ }^{3}$. Nous nous sommes très vite aperçues que nous parlions la même langue. Nos opinions convergeaient sur des questions prioritaires telles la survie culturelle des petites communautés, en danger dans le monde entier, la défense des identités autochtones et indigènes et la préservation de tous les éléments de leur culture. En fait, les membres de la commission dans leur quasitotalité soutenaient ces principes, qui devinrent le sujet principal du rapport. La polysémie du terme "culture" créait cependant d'infinis problèmes de compréhension. À tel point que, pour ménager un consensus, la référence vague à des "façons de vivre ensemble» fut adoptée comme définition fonctionnelle.

Comme la commission était officiellement indépendante - chaque courant politique et intellectuel essayant bien sûr de l'influencer -, nous avons pu discuter librement, emplissant la plupart de nos réunions de débats intellectuels. Je pris bientôt conscience qu'au-dessus de nous planaient ce que Chérif Khaznadar a subtilement nommé le "partiellement dit», la volonté de maintenir un équilibre entre les États membres de l'Unesco, et le «non-dit», en l'occurrence la volonté d'influencer le rapport (Khaznadar 2009). Je découvris de plus que ces deux niveaux déterminaient la dynamique réelle des discussions car l'obtention d'un consensus et la diplomatie exigeaient que certaines choses fussent passées sous silence. Pour une anthropologue convaincue que la qualité et la profondeur d'une analyse de terrain se jaugent à la façon dont les tours et les détours des dissensions internes sont mis au jour, le non-dit s'avérait difficile à accepter.

Mes «notes de terrain" lors des réunions montrent que, tandis que Nakane et moi-même défendions la position selon laquelle il fallait prendre le temps de consolider les connaissances scientifiques sur des sociétés majoritairement autochtones, d'autres membres de la commission faisaient des propositions liées aux priorités politiques de tel ou tel pays ou bloc
3. Cette commission comprenait également des économistes, des représentants gouvernementaux pour la culture, des dirigeants de communautés indigènes, des philosophes et des cinéastes. 
4. Ces consultations se tinrent à Paris, San José (Costa Rica), New York, Manille, Abidjan (transférée à Paris), Moscou, Oman, Pretoria et Chiba (Japon).

5. Parmi les intervenants figuraient Johan Karl Kleber - qui le premier proposa de créer la commission Élie Wiesel, le ministre de la Culture de Norvège Ase Kleveland, Jacques Derrida, Alain Touraine, Edith Sizoo, Catherine Lalumière, Mishio Morishima, Marc Ferro, Gert Rosental, Fernando Calderón, Rex Nettleford, Nestor García Canclini, Roberto da Matta, Alan Tonelson, José Joaquín Brunner, Yao Jie Hou, Kapila Vatsayanan, Stephen Yeh, San Bok Han, Stephen Hill, Khaled Bin Taleb Al Zakwani, Anouar Abdel Malek, Werewere Liking, Yoro Fall, John Cosne, Olivia Muchena, Mamadou Dia, Samba Sar et d'autres encore dont les contributions ont marqué le contenu du rapport. Voir Commission mondiale de la culture et du développement, Notre diversité créatrice,

Paris, Unesco, 1996. régional. Peu après cependant, je retrouvai le cadre de mon travail habituel d'anthropologue au fur et à mesure que de plus en plus d'érudits, d'artistes et de politiciens étaient sollicités au cours des neuf consultations régionales ${ }^{4}$. Ils brossèrent un tableau d'une ampleur fascinante introduisant aux finesses philosophiques et politiques des cultures du monde, richesse que nous avons eu du mal à intégrer au texte du rapport ${ }^{5}$. En écoutant leurs déclarations multiples au croisement de courants culturels mondialisés se chevauchant et fusionnant les uns avec les autres, j'ai dû changer mon point de vue. Je devais aller au-delà de ma perspective d'anthropologue pour devenir un agent culturel contribuant au vivre ensemble de toutes les sociétés et cultures du monde. Dans un sens, en devenant cet agent culturel, je participais à l'activation d'un processus consistant à trouver de nouveaux mots, de nouveaux débats et des arguments de négociation différents sur une planète de plus en plus mondialisée.

Si impressionnés que nous fussions par ce trésor philosophique et culturel mondial, nous, les commissaires, dûmes faire face à une urgence: écrire un rapport pouvant offrir au monde un ensemble de concepts et de principes directeurs clairs et accessibles, susceptible de créer un espace commun où livrer les batailles sur l'avenir de la relation entre les cultures et le développement. Cela supposait de réduire considérablement l'éventail des sujets ainsi que leur complexité pour se concentrer sur quelques thèmes et développer des lignes d'action spécifiques en politique internationale de la culture.

Les pays membres de l'Unesco réclamaient en urgence la définition de principes directeurs des politiques culturelles et programmes internationaux pour parer à la perte des cultures traditionnelles face à la mondialisation. Cette urgence, en fait, tomba sous ma responsabilité en plein milieu des consultations régionales. Mayor et Pérez de Cuéllar, préoccupés par certains problèmes dans l'élaboration du rapport, me demandèrent de m'occuper du secrétariat chargé de le rédiger. En ce qui concerne le rapport de la commission, à présent appelé Notre diversité créatrice, les commissaires m'ont priée de m'assurer que le texte qu'ils avaient adopté serait bien celui présenté à la Conférence générale de I'Unesco en 1995.

À propos du patrimoine culturel, Notre diversité créatrice soulignait que les guerres, les désastres environnementaux et le développement inconsidéré mettaient plus que jamais en danger le patrimoine naturel et culturel de l'humanité. Le rapport demandait aux communautés locales aussi bien qu'aux institutions internationales de relever le défi consistant à sauvegarder et revitaliser ce patrimoine par leurs efforts conjugués. Ce chapitre, auquel le personnel de l'Unesco a contribué, mettait l'accent sur le fait que le patrimoine culturel ne se compose pas seulement de sites et de monuments, d'une multitude d'objets d'art et d'artisanat, de documents et de manuscrits, mais aussi de traditions orales et de l'expression culturelle sous toutes ses formes, y compris les arts du spectacle. Sauvegarder ces créations du passé, cependant, devrait aller de pair avec l'encouragement à la création dans l'art et la culture contemporains. Les interprétations et l'usage actuels de ce patrimoine culturel, notait le rapport, tendaient encore à être dominés 


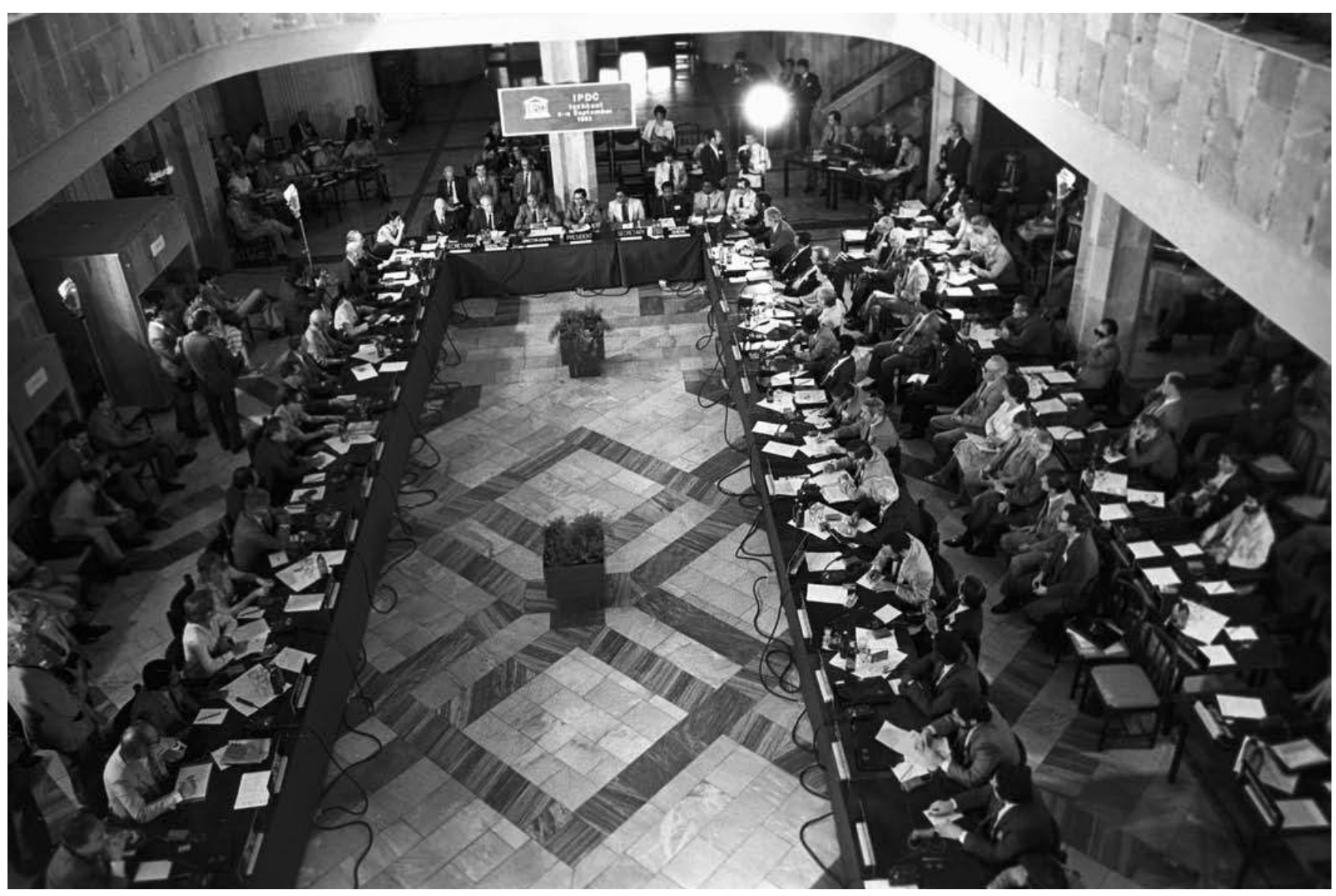

fig. 2

La IVe session

intergouvernementale

de l'Unesco à Taschkent

(Uzbekistan), 1983.

(C) Utarbekov/RIA NOVOSTI. 
par des critères à la fois esthétiques et historicistes. II était nécessaire de les élargir afin que chaque société puisse évaluer la nature, voire la précarité, de ses ressources patrimoniales et décider comment les inscrire dans le monde contemporain. Notre diversité créatrice mettait noir sur blanc la mission de I'Unesco: jeter les fondations du patrimoine culturel immatériel.

\section{Les premières discussions sur le patrimoine culturel immatériel}

En 1994, le processus de révision de la liste du patrimoine mondial avait déjà commencé. La conférence de Nara, au Japon, avait ouvert les critères d'inclusion en reformulant la notion d'authenticité (Bortolotto 2011) et en prenant en compte d'autres acceptions du patrimoine culturel. Sous la pression des pays d'Afrique et d'Asie de l'Est, le comité qui examina la liste du patrimoine mondial jugea que le patrimoine physique construit, les monuments religieux européens, le patrimoine produit par des hommes plutôt que par des femmes et celui de l'Antiquité étaient surreprésentés, évinçant ainsi des monuments et sites plus contemporains. En conséquence, lors de réunions ultérieures autour de la liste du patrimoine mondial furent incluses entre autres la ville moderne de Brasilia et, grâce à la catégorie nouvelle de «paysage culturel», les rizières en terrasses des Philippines et les plantations de café à Cuba.

Lors de la réunion du Comité exécutif qui eut lieu en 1994 - je venais d'être nommée directrice adjointe pour la culture -, nombre d'États membres saisirent cette occasion pour exiger des changements dans la politique de l'Unesco concernant le patrimoine culturel. Dans le superbe cadre de Fès, au Maroc, des délégations de pays émergents exprimèrent leur volonté de conserver vivantes leurs traditions culturelles tout en évitant une «muséification " des centres historiques dans certaines villes ou une «folklorisation» de leurs très anciennes traditions locales. Ils proposèrent des activités générant des revenus fondées sur leurs compétences culturelles et artisanales, des programmes de soutien aux autochtones vivant dans des habitats menacés, et la promotion de la richesse de leurs expressions culturelles et de leurs «trésors culturels vivants ».

Parmi ces représentants gouvernementaux et ces délégués, beaucoup se souciaient sincèrement de sauvegarder leur culture et leur identité, et se consacraient à cet objectif avec conviction. Certains, confrontés à des forces opposées dans leur propre pays, cherchaient le soutien de l'Unesco à leur cause. Il est intéressant de noter que les officiels ayant été impliqués dans la politique culturelle de leur gouvernement étaient d'accord avec la Commission mondiale sur la culture et le développement, à savoir que monuments, sites, objets et spectacles n'acquièrent de la valeur qu'à travers l'intersubjectivité d'où naît la volonté de sauvegarder ces pratiques. Cette dernière devait être vivifiée par la reconnaissance, l'action et le renouvellement.

\section{Les premiers pas vers la Convention de 2003}

Je me rappelle le jour où Noriko Aikawa-Faure, alors directrice du Département des langues dans le Secteur de la culture, se présenta dans mon bureau et me dit: «Vous êtes ethnologue: aidez-nous à revitaliser la 
Recommandation sur la sauvegarde des cultures et du folklore traditionnels. " J'étais tout à fait convaincue de la nécessité d'un instrument international normatif dans ce domaine puisque nous l'avions mentionné dans le rapport Notre diversité créatrice. Plusieurs pays s'étaient déjà rapprochés dans ce but. Le Japon et la Corée aussi bien que les délégations africaines avaient constamment montré un grand intérêt pour ce projet. Ayant exercé la fonction de directrice du musée national des Cultures populaires au Mexique (1985-1988), je connaissais la difficulté à transformer des idées en projets culturels proactifs auxquels les gouvernements et les groupes locaux pouvaient participer, puis développer de leur propre chef. Aussi ai-je pleinement soutenu le programme d'Aikawa-Faure visant à organiser cinq rencontres sur ce sujet dans différentes régions. En même temps, Notre diversité créatrice une fois lancée, se tinrent plusieurs réunions avec pour propos de définir indicateurs et indices portant sur la culture et le développement. Les concepts qui faisaient l'objet de ces discussions tels que, entre autres, «développement culturel», «liberté culturelle», «diversité culturelle», donnèrent des pistes importantes pour réorienter les programmes de l'Unesco en termes de «pratiques vivantes» et surtout «significatives» qui devraient être reconnues, préservées et réinventées dans les politiques culturelles.

L'expression spécifique «patrimoine culturel immatériel» avait été précédemment mentionnée dans les résolutions et les programmes de I'Unesco, mais fut définie durant les réunions organisées par Aikawa-Faure auxquelles participèrent beaucoup d'anthropologues, en particulier Georges Condominas. Nous tentâmes à plusieurs reprises de créer un nouveau terme qui contournerait les problèmes théoriques posés par «cultures traditionnelles» et «folklore». Citons, parmi les différentes propositions: «culture expressive», «expression de soi », «patrimoine philosophique», «patrimoine intellectuel », et d'autres, plus extravagantes. La discussion était centrée sur deux axes: matériel-immatériel, et le degré de formalisation des pratiques culturelles. Survint aussi le problème des différences lexicales dans des langues diverses, «intangible» ne signifiant pas exactement la même chose en anglais et en français, celui-ci ayant jusqu'alors utilisé le mot «immatériel». Finalement, l'expression «patrimoine culturel immatériel» fut retenue, bien que nous fussions tous conscients du fait que cette sorte de patrimoine est évidemment en grande partie tout à fait tangible, par exemple lorsqu'il s'agit d'instruments de musique, de masques et ainsi de suite. Cette expression ne répondait pas entièrement à ce que nous visions, mais, comme il en est de tant d'autres formules, nous espérions qu'avec le temps elle acquerrait la connotation qui permettrait de l'utiliser dans le but requis.

Ces réunions sur les indicateurs culturels et le patrimoine culturel immatériel me donnèrent l'occasion d'ancrer solidement le changement de perspective sur la culture à l'Unesco. Dans la brochure du Secteur de la culture publiée à ma demande pour la Conférence générale de 1997, j'ai donné la définition suivante: «La culture est le flux continuel de sens que les gens créent, mêlent et échangent. Elle nous donne la possibilité d'élaborer des héritages culturels à travers lesquels notre vie se perpétue. Elle nous permet de reconnaître nos liens avec les nôtres, la communauté, les groupes linguistiques et les États-nations, autant 


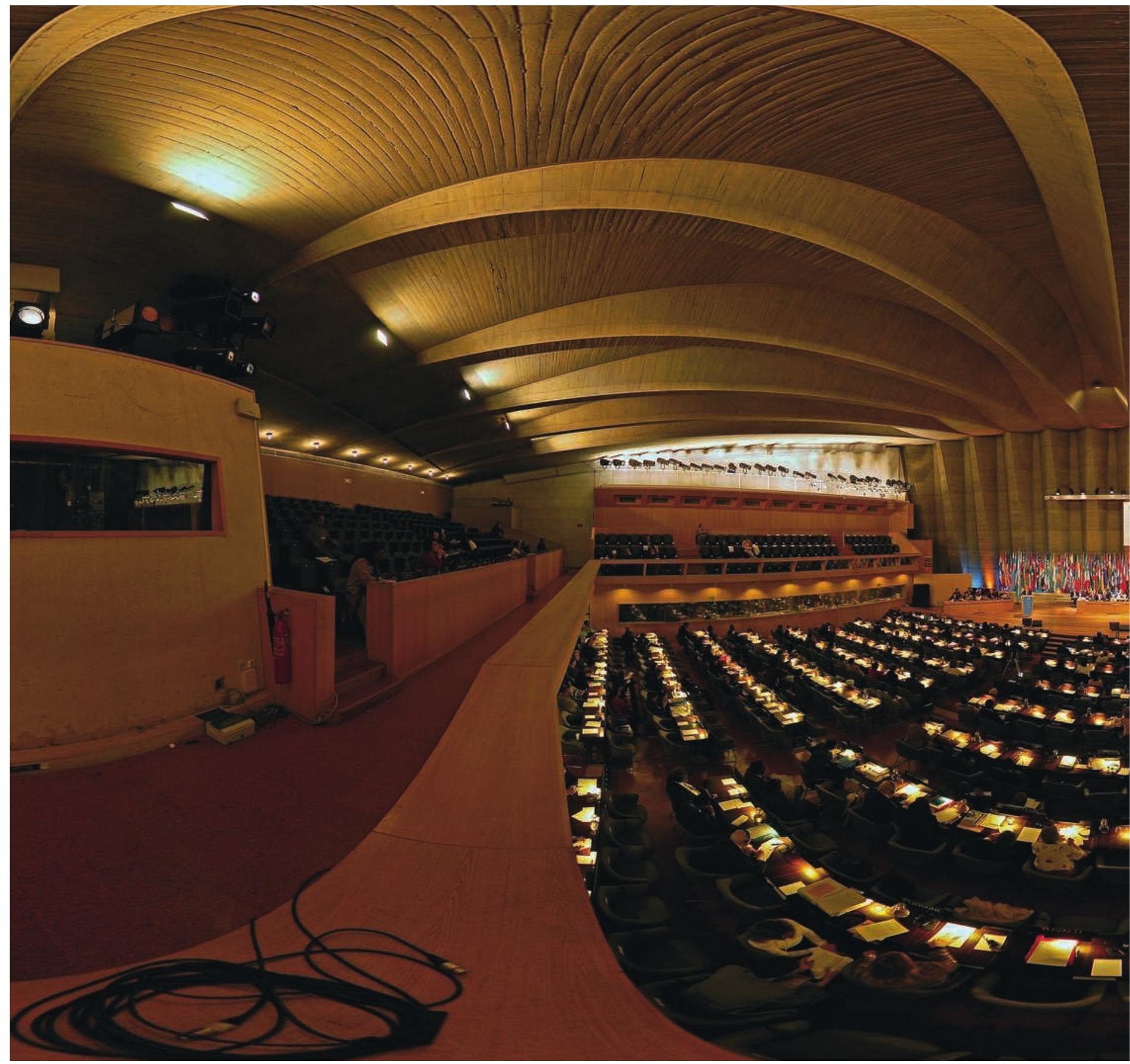




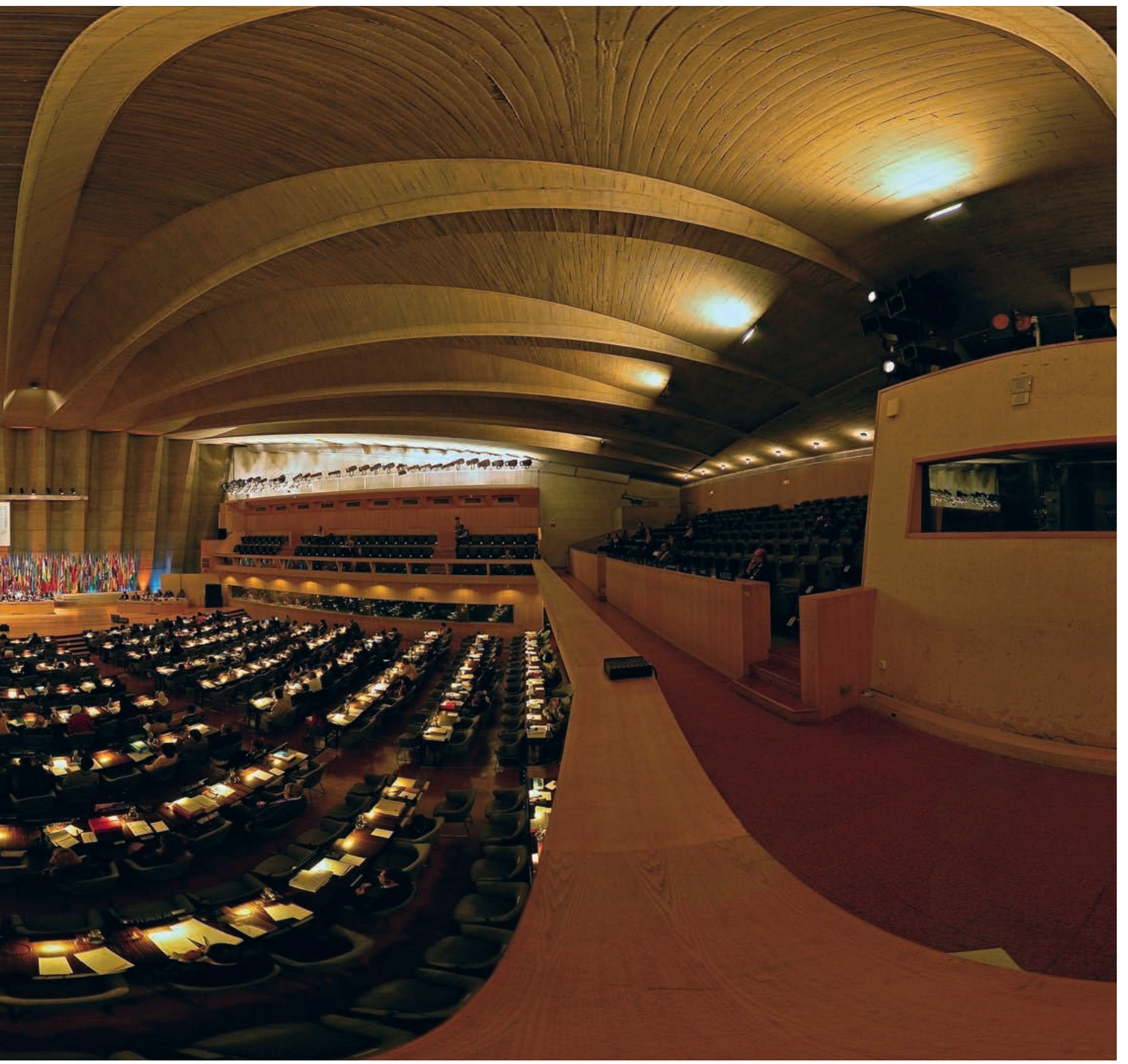

fig. 3

Siège de l'Unesco, salle I,

v. 2005. (C) Panophotographie

de Tito Dupret. 


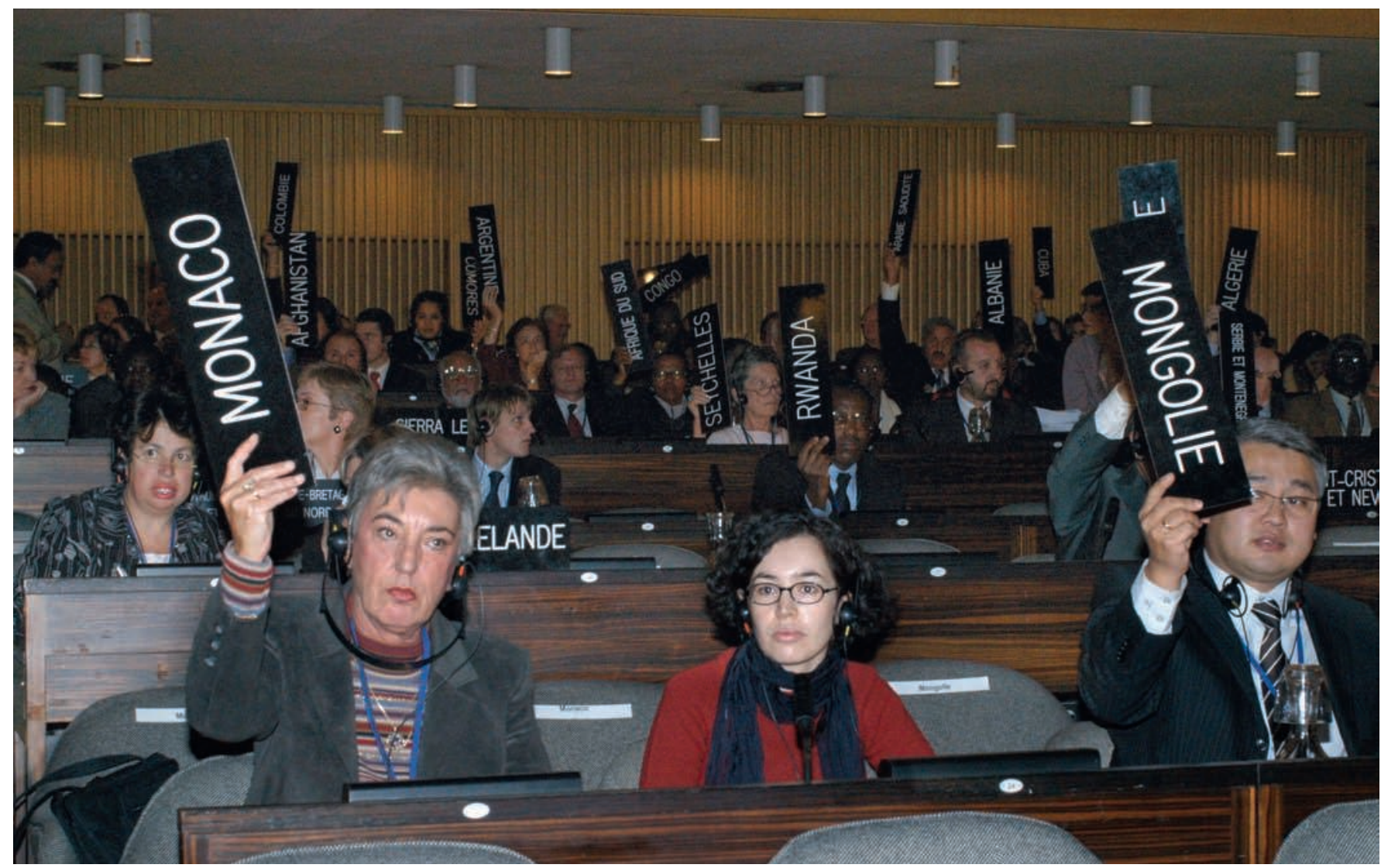

fig. 4

Vote de la Convention internationale pour la sauvegarde du patrimoine immatériel, 2003. (C) Andrew Wheeler/Unesco.
6. Du tissage à la Toile... L'Unesco célèbre la culture, brochure sur les programmes du Secteur de la culture pour la Conférence générale, Paris, Unesco, 1998.

7. Ibid.

8. J'avais été élue viceprésidente et, par la suite, présidente du Conseil international des sciences sociales, organisation fondée en 1952 par l'Unesco. qu'avec l'humanité elle-même. Elle nous aide à mener une existence empreinte de sens. Et pourtant la culture peut nous amener à porter nos dissensions en bannière dans la guerre et l'extrémisme. On ne doit donc pas considérer qu'elle va de soi, mais la travailler avec soin pour qu'il en sorte des réalisations positives [...] à l'heure où les peuples de toutes cultures sont plus que jamais en contact les uns avec les autres, ils se posent la même question quand ils se voient: comment pouvons-nous préserver notre patrimoine? Comment nos multiples cultures peuvent-elles coexister dans un monde interactif 6 ? »

Cette publication contenait une section sur «Les formes d'expression de soi : le patrimoine immatériel», où il était expliqué que «[...] le patrimoine culturel mondial comprend aussi ses traditions orales, ses langues, sa musique, sa danse et ses arts du spectacle, son artisanat et ses coutumes [...] I'Unesco est attentive depuis longtemps à la préservation de ces formes d'expression en perpétuel changement. Cependant, ce programme élargi apporte une impulsion nouvelle ${ }^{7}[\ldots]$. »

En 1998, après avoir démissionné, je retournai à l'Université nationale de Mexico, mais continuai de participer très activement à la recherche en sciences sociales au plan international ${ }^{8}$. Comme conseillère sur le patrimoine culturel immatériel, je pouvais plus librement proposer des idées, mais par la suite, lorsque les délégations gouvernementales insistèrent 
pour que les «experts» soient nommés seulement par les gouvernements, je disposais d'un accès plus limité aux réunions essentielles où se prenaient les décisions ${ }^{9}$.

\section{Le patrimoine culturel immatériel, définitions: les droits de l'homme et les domaines culturels}

Koïchiro Matsuura, élu directeur général de l'Unesco en 2000, fit de la Convention pour la sauvegarde du patrimoine culturel immatériel l'un de ses projets phare. II organisa une table ronde internationale sur «Le patrimoine culturel immatériel, définitions opérationnelles » qui se tint en Italie, à Turin, afin de définir l'espace et les éléments qui devraient être protégés par un instrument légal international. II me demanda de préparer l'entrée en matière.

Je déclarai dans mon discours que la notion de patrimoine était faite de sens, un sens forgé par les perceptions des gens, qu'il s'agisse d'objets, de connaissances ou de pratiques (Unesco 2001). J'expliquai que le patrimoine immatériel se définissait essentiellement par sa mise en pratique. II se distingue en cela du patrimoine physique dans la mesure où il existe et demeure par les actions humaines. Partant de là, selon moi, il faudrait comprendre par patrimoine culturel immatériel un processus de création englobant les compétences, les produits, les significations, les impacts et la valeur économique. Je développai chaque point. Les instruments de sauvegarde du patrimoine culturel immatériel devraient donc aussi protéger ce processus de création qui nous a légué des réalisations de très grande valeur et doit se perpétuer, de telle sorte que nos sociétés puissent continuer de créer leur propre avenir.

À la question de savoir pourquoi un instrument légal était nécessaire, je répondis de la façon suivante:

- Afin de conserver des créations humaines qui pourraient disparaître à jamais. Au nom du postulat selon lequel a) les créations humaines ont de la valeur; b) la diversité des créations humaines a de la valeur pour l'humanité. - Afin de conférer une reconnaissance mondiale à un certain type de patrimoine culturel immatériel. Au nom du postulat selon lequel a) tous les habitants de la planète ont intérêt à conserver un tel patrimoine; b) nations et groupes gagneront à obtenir cette reconnaissance de leur patrimoine car «la fierté de quelques-uns devient celle de tous».

- Afin de renforcer les identités, qu'elles soient locales, ethniques, culturelles ou nationales.

- Afin de rendre possible la coopération sociale à une époque où le marché et le consumérisme valorisent l'individualisme.

- Afin d'apporter une continuité historique à ceux qui ont psychologiquement besoin d'appartenir à une tradition historique.

- Afin de créer du plaisir.

Dans ma présentation, voici les domaines du patrimoine culturel immatériel que je proposai et que selon moi l'Unesco pouvait traiter, munie d'une base théorique solide et d'un avantage comparatif spécifique par rapport à d'autres institutions nationales et internationales, pour développer un nouvel instrument légal international ${ }^{10}: 1$ ) les pratiques sociales de cohésion; 2) les traditions orales; 3) les fêtes; 4) les croyances sur la nature
9. Les gouvernements de droite au Mexique (20002012) ont considérablement affaibli la participation internationale de ce pays et ont été empêchés de fermer la délégation mexicaine à l'Unesco grâce aux protestations de plusieurs scientifiques et intellectuels mexicains.

10. En tant que directrice générale adjointe de la culture, j'avais été chargée des relations avec d'autres institutions internationales qui menaient depuis peu des programmes liés à la culture, notamment la Banque mondiale, l'Organisation mondiale de la propriété intellectuelle (OMPI) et l'Organisation mondiale du commerce (OMC). Celles-ci définissaient la culture en termes de propriété. Comme on pouvait s'y attendre, de nombreuses batailles, conceptuelles et institutionnelles, s'ensuivirent. 
11. Je les avais exclues pour deux raisons: d'abord, j'avais trouvé que mes explications scrupuleuses aux délégations et au personnel de l'Unesco sur la différence entre langue, dialecte et variantes qui ne permettait pas d'affirmer brutalement l'existence de 6000 langues dans le monde, dont 3000 en voie de disparition, ne faisaient que décevoir les participants à ces programmes et retarder les chances de parvenir à un consensus. Je revins donc sur ma décision de ne citer aucun chiffre concernant les langues. Voilà un nouvel exemple de la manière dont, en matière de prise de décision participante, je me retrouvai face à un dilemme entre le souci d'assurer la précision de l'information anthropologique et la stratégie discursive requise pour convaincre les délégations de la nécessité d'agir. Ensuite, parce que des pays émergents où existent des centaines de langues m'avaient demandé de laisser ce domaine en dehors de la Convention de 2003 à cause des risques de conflits intérieurs auxquels ils pourraient être confrontés.

Finalement, je suis restée ferme sur ma décision de plaider pour une politique de trilinguisme, à savoir une langue vernaculaire, une nationale et une internationale, position qui a paru choquer tout le monde mais que malgré son impopularité je continue de défendre à ce jour. et le cosmos. Que les langues n'y fussent pas incluses sema le trouble parmi les participants à la réunion ${ }^{\mathbf{1 1}}$. Elles devinrent un domaine à part entière lors de réunions ultérieures.

Peter Seitel, un anthropologue américain, mit en lumière le rôle central que pourraient jouer les gardiens des traditions, en tant que partenaires et experts, dans la sauvegarde du patrimoine culturel immatériel. Créateurs eux-mêmes, détenteurs de connaissances et transmetteurs conscients de leurs traditions, ils méritent une meilleure reconnaissance. Seitel élargit la portée de son propos en attirant également l'attention sur le fait que le patrimoine culturel immatériel pouvait être hybride et créole si l'on se référait à des critères comme la profession ou les activités féminines.

II convient ici de mentionner que ce dernier sujet fit ensuite l'objet d'une réunion de l'Unesco sur «Les femmes et le patrimoine culturel immatériel». Beaucoup d'études anthropologiques, rappelant le voile mis sur la participation des femmes dans les processus culturels, avaient montré leur rôle particulièrement important dans les pratiques sociales et les rituels. Dans son livre déterminant, The Gender of the Gift (1989), Marilyn Strathern démontrait que le travail des femmes et leurs réseaux très développés étaient essentiels pour l'accomplissement des rituels; par ailleurs, à travers les relations sociales, elles contribuent à valoriser les objets et d'autres formes de patrimoine culturel immatériel. Les femmes ne sont pas des "gardiennes des traditions» passives, ni de simples «courroies de transmission » du patrimoine culturel immatériel. Elles doivent pourtant faire face à un «paradoxe crucial», selon la formule d'Adriana González Mateos (2003) lors de son intervention à la table ronde. «Pour se libérer des contraintes traditionnelles, écrivait-elle, elles considèrent la modernisation comme un choix libérateur [...] alors qu'une stratégie plus sournoise, afin de les maintenir assujetties à ces contraintes, souligne leur rôle de gardiennes de la tradition. »

Le plan d'action final adopté par la table ronde internationale de Turin faisait valoir trois points: a) la participation active des agents/créateurs de la culture concernée devrait être recherchée à toutes les étapes - identification du projet, allocation des ressources, planification et exécution; b) cette participation devrait s'appuyer sur une compréhension du patrimoine culturel immatériel centrée sur les gens et le processus; c) les efforts internationaux autour de la préservation du patrimoine culturel immatériel devraient reposer sur les droits de l'homme universellement acceptés, les principes d'équité et de durabilité ainsi que le respect de toutes les cultures qui respectent les autres cultures.

Le colloque de Turin avait établi le cadre de travail en termes de droits de l'homme, ainsi que les domaines et les définitions applicables à d'autres éléments du patrimoine culturel immatériel. Ensuite vint l'exercice majeur consistant à trouver une compatibilité entre le langage des anthropologues et celui des juristes. Les débats furent loin d'être sereins. La rigueur scientifique exigée par les anthropologues et autres spécialistes, nous le découvrîmes vite, devint vague et informe confrontée à la méticuleuse nécessité de précision et de forme exigée par les experts juridiques. 


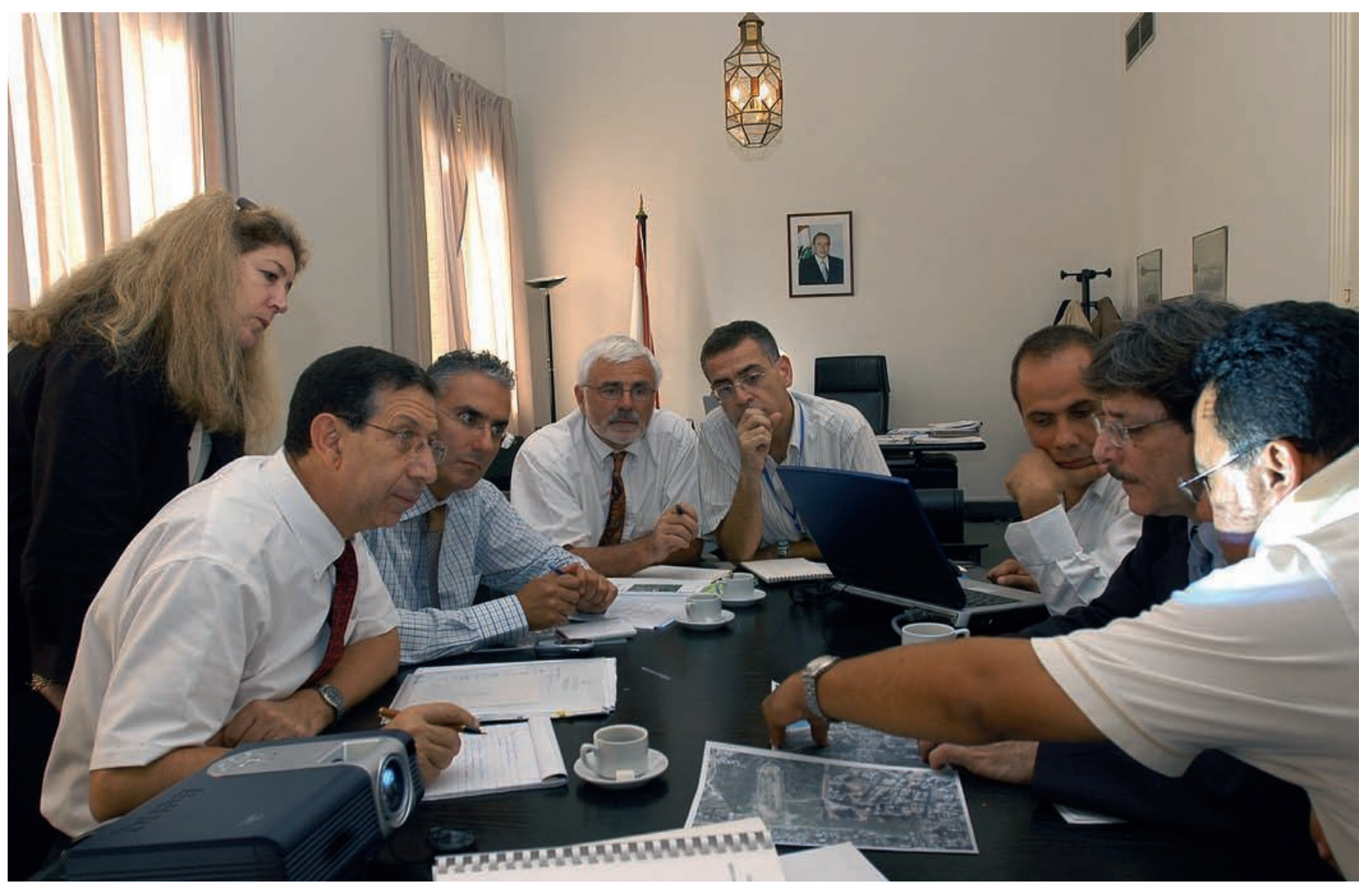

fig. 5

Réunion technique de

la mission Unesco dirigée par M. Mounir Bouchenaki, Directeur général du Centre international d'études pour la conservation et la restauration des biens culturels (ICCROM) avec des experts de la Banque Mondiale et M. Frédéric Husseini, Directeur général des Antiquités du Liban, Beyrouth, 2006. (C) Claudio Bruno Monteiro/Unesco. 
À l'occasion de la réunion d'experts sur la terminologie qui se tint à Paris du 10 au 12 juin 2002, j'esquissai en guise d'introduction le contexte dans lequel le patrimoine culturel immatériel devait être défini. Il fallait, selon moi, condenser un siècle de débats sur la culture et les changements politiques dans les sciences sociales. J'insistai sur la priorité que l'on devait donner aux communautés porteuses de culture et à l'agentivité locale; pour moi, sauvegarder était inenvisageable en dehors des conditions créant et recréant le patrimoine culturel dans le temps, avec une attention particulière aux interactions sociales qu'implique toute réalisation, parmi lesquelles l'impératif de tolérance politique et religieuse. Empêcher la réification de la culture en insistant sur l'agentivité humaine, c'était la priorité des priorités pour les anthropologues que nous étions (Unesco 2002).

Antonio Augusto Arantes releva que le patrimoine culturel immatériel représentait en premier lieu une ressource permettant aux gens de vivre, et non quelque chose que l'on peut simplement consigner. Aussi les membres de la communauté devraient être à même de décider quel patrimoine sauvegarder et comment le faire évoluer. Nous étions déjà plusieurs à nous préoccuper de la possible appropriation des ressources culturelles locales par des personnes étrangères aux communautés, comme on pouvait le constater dans certaines communautés indigènes, en particulier en Amérique latine.

Susan Wright souleva par ailleurs une autre question majeure qui fut maintes fois discutée par la suite à l'Unesco, à savoir qui devrait être habilité à définir le patrimoine culturel immatériel dans chaque cas spécifique. Ceci reflète les discussions ayant actuellement cours en anthropologie sur les "gardiens" culturels, c'est-à-dire les dirigeants nommés par la communauté ou autoproclamés qui peuvent jouer un rôle positif ou négatif en sauvegardant les cultures locales ou en s'opposant à leur changement. Nous fûmes tous d'accord sur le fait que tout instrument légal international devait garantir que les praticiens culturels soient eux-mêmes partie prenante dans ce genre de décision.

Aussi, au moment d'établir un glossaire, les anthropologues ont considéré que la culture en tant qu'entité abstraite, immuable, existant en soi et tombée du ciel devrait être redéfinie dans des termes plus spécifiques. Nous avons proposé "porteurs de culture» en tant que "membres d'une communauté qui s'emploient activement à reproduire, transmettre, transformer, créer et façonner la culture... " Autrement dit, des "créateurs", «praticiens» et «conservateurs» dynamiques, spécialistes du patrimoine. Comment définir la relation de ces "créateurs" et «praticiens" aux communautés culturelles? Dans le glossaire, "communauté» signifiait «des gens qui partagent un sens du lien décidé par eux-mêmes". II est important de signaler que les anthropologues, en accord avec la perspective unesquienne d'«allégeances multiples ", tinrent à préciser que les individus pouvaient appartenir à plus d'une communauté. La "communauté culturelle " fut alors définie comme «se distinguant des autres communautés par sa culture ou son dessein culturel propres, ou par une variante de la culture générique». Et, pour clore un débat depuis longtemps récurrent chaque fois que l'on parlait de culture à l'Unesco, il fut précisé que «parmi d'autres 
extensions possibles, une nation peut être une communauté culturelle»; on évacuait ainsi le problème posé par le monopole des minorités sur le patrimoine culturel immatériel. Une clarification pertinente affirmait que chaque «communauté indigène» était définie en tant que «communauté dont les membres se considèrent comme originaires d'un certain territoire ». Ceci n'exclut pas «l'existence de plus d'une communauté indigène sur le même territoire».

Beaucoup de débats ont tourné autour d'une question importante: peut-on appliquer les instruments utilisés pour le patrimoine physique au patrimoine immatériel? Paul Kuruk, à l'occasion de la même réunion, apporta une précision en vue de la Convention: sur le plan légal, on avait préféré, au lieu de «conservation » ou «protection», le terme «sauvegarder». L'on mettait donc en relief le fait qu'il fallait «adopter des mesures assurant la viabilité du patrimoine culturel immatériel, y compris l'identification, la documentation, la protection, la promotion, la transmission et la revitalisation de certains aspects de ce patrimoine». Cette distinction cruciale entre les deux types de patrimoine reconnaît que le patrimoine culturel immatériel se réalise et s'accomplit afin de constamment restaurer son sens.

Après toutes ces délibérations, la définition suivante du patrimoine culturel immatériel et de ses domaines constitutifs fut approuvée:

(i) Aux fins de la présente Convention, on entend par «patrimoine culturel immatériel » les pratiques, représentations, connaissances et savoir-faire - ainsi que les instruments, objets, artefacts et espaces culturels qui leurs sont associés - que les communautés et les individus reconnaissent comme faisant partie de leur patrimoine culturel immatériel, et qui sont conformes aux principes universellement acceptés des droits de l'homme, de l'équité ainsi qu'à l'exigence du respect mutuel entre communautés et d'un développement durable. Ce patrimoine culturel immatériel, transmis de génération en génération, est recréé en permanence par les communautés en fonction de leur milieu, de leur interaction avec la nature et de leur histoire, et leur procure un sentiment d'identité et de continuité, contribuant ainsi à promouvoir le respect de la diversité culturelle et la créativité humaine. (ii) Le patrimoine culturel immatériel, tel que défini au paragraphe (i) ci-dessus, embrasse les domaines suivants: 1) les expressions orales, 2) les arts du spectacle, 3) les pratiques sociales, rituels et événements festifs et (4) les connaissances et pratiques concernant la nature.

Le glossaire, diffusé comme document préliminaire au sein de l'Unesco après une discussion prolongée entre le personnel de l'Organisation et le rapporteur de la réunion, l'anthropologue néerlandais Wim van Zanten, ne fut jamais envoyé officiellement aux délégations des États membres. Les délégations gouvernementales exigèrent alors que tous les experts nommés par les gouvernements le soient parmi leurs membres. Cette décision, de même que d'autres, prises en vue de la Convention, changea la nature discursive d'une convention internationale telle qu'on la concevait jusque-là à l'Unesco. En un sens, il s'agissait de la tentative 


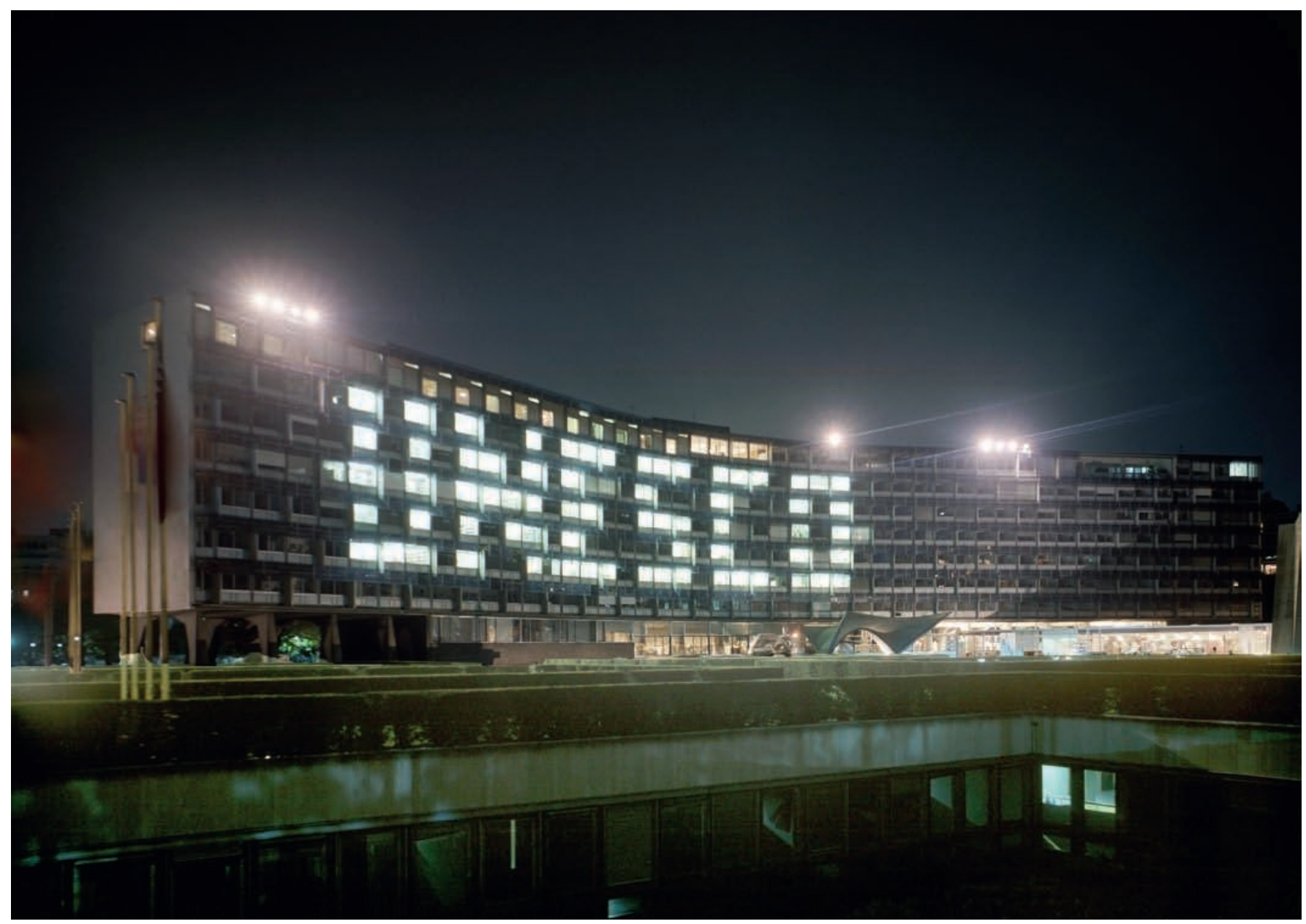

fig. 6

Le siège social de l'Unesco illuminé, s.d. () Guy Nicolas/ Unesco. 
de quelques délégations des pays membres pour établir une convention «dérégulée».

Lors d'une réunion qui se tint quelques mois plus tard à la Maison des cultures du monde, à Paris, les délégués déclarèrent ne pas vouloir de normes et de standards appliqués à la Convention ni de spécialistes ou d'organisations scientifiques internationaux intervenant en tant que conseillers. En levant les barrières qui limitaient les inscriptions sur la liste représentative de la Convention $\mathbf{1 2}$, on avait en fait facilité l'adoption, la ratification et l'application de la Convention de 2003. En revanche, il reste que pour chaque norme régulatrice éliminée un nouveau danger surgissait dans l'élaboration des listes. Ce n'est pas ici le lieu d'analyser ces dangers, mais tout le monde connaît bien les problèmes posés par le manque de clarté conceptuelle et opérationnelle du terme "représentativité" du fait des hiérarchies introduites dans le choix des éléments à inclure dans les listes, lesquels laissaient de côté les agents locaux, et de l'hyper-politisation des décisions concernant les listes. Ainsi, les groupes les plus influents politiquement, intervenant de façon incontrôlable aussi bien au niveau national qu'international, orientaient les décisions au sein des organes de la convention, ce qui finissait par remettre en question la légitimité de la liste représentative.

Je terminerai en ajoutant que toutes ces questions refirent surface lors de la réunion célébrant le dixième anniversaire de la Convention de 2003, à Chengdu. Lorsque se tint la commission finale intitulée «Questions ouvertes et directions futures ", je remarquai brièvement que a) les praticiens culturels ne sauvegardent plus leur patrimoine culturel immatériel mais, en fait, le reconfigurent; b) l'absence de débat en profondeur et de longue durée sur les types de patrimoine culturel immatériel présents dans les listes de la Convention de 2003 rend les délégations et le personnel de l'Unesco vulnérables aux manipulations politiques et économiques et altère la reconnaissance culturelle des pratiques; c) le locus de la production culturelle se déplace rapidement vers le monde virtuel et les réseaux sociaux, ce qui doit être pris en compte à la fois dans la consignation, la reconfiguration et la propagation du patrimoine culturel immatériel; d) le patrimoine culturel immatériel doit être reconceptualisé dans un nouveau cadre ontologique écologico-social, ainsi que l'a proposé, entre autres, Philippe Descola; e) la vague d'enthousiasme qui a saisi le monde entier - on le voit aisément à la prolifération des prises de vue spontanées sur le patrimoine culturel immatériel mises en circulation par des jeunes gens, notamment sur YouTube - montre à quel point le concept de patrimoine culturel immatériel est pertinent, opportun et plein d'avenir tant que nous ne le considérons pas comme un vestige du passé mais comme un espace privilégié de débat et de création.
12. La convention établit deux listes: la Liste dite de "sauvegarde urgente" composée d'éléments dont la transmission est menacée et la Liste représentative qui promeut la visibilité des éléments inscrits et la prise de conscience de

l'importance du patrimoine culturel immatériel. 


\section{Arizpe, Lourdes}

1996 «L'innovation et la technologie au service du patrimoine de l'humanité", in Actes du colloque "Innovation et technologie au service du patrimoine de l'humanité".

Paris, Association pour le développement du mécénat fondé sur l'innovation et la technologie (Admitech) et Unesco.

2006 "The intellectual history of culture and development institutions ", in Robert Walton et Rao Vijendra (éd.), Culture and Public Action. Palo Alto, Stanford University Press.

2008 "The value of ritual: Aesthetics and commitment", in Michael Hutter et David Throsby, Beyond Price: In Search of Cultural Value. Cambridge, Cambridge University Press: 141-159.

2011 Compartir el patrimonio cultural inmaterial: narrativas y representaciones. Mexico, Consejo Nacional para la Cultura y las Artes et Université nationale du Mexique.

À paraître "Culture, diversity and heritage: Major studies", Springer Briefs on Pioneers in Science and Practice 11, Subseries Texts and Protocols 6. Heidelberg-DordrechtLondres-New York, Springer Verlag.

\section{Arizpe, Lourdes et Amescua, Cristina}

2013 "Anthropological perspectives on intangible cultural heritage", Springer Briefs in Environment, Security, Development and Peace, vol. VI. Heidelberg-Dordrecht-LondresNew York, Springer Verlag.

\section{Bortolotto, Chiara}

2011 « II patrimonio immateriale e l'autenticità: una relazione indissolubile ", La Ricerca Folklorica 64: 7-17.

\section{Gonzàlez Mateos, Adriana}

2003 «Mexican women migrants in New York and the paradox of modernizing their cultural heritage", communication lors de la réunion de l'Unesco sur «Les femmes et le patrimoine culturel immatériel ».

\section{Khaznadar, Chérif}

2009 «Les dangers qui

guettent la Convention de 2003 ", in Le Patrimoine culturel immatériel à la lumière de l'Extrême-Orient.

Paris, Maison des cultures du monde: 13-46.

\section{Strathern, Marilyn}

1989 The Gender of the Gift. Cambridge, Cambridge University Press.

\section{Unesco}

2001 Le Patrimoine culture immatériel, définitions

opérationnelles. Table ronde internationale, rapport final.

2002 Terminologie et patrimoine intangible. Projet de glossaire.

Réunion d'experts sur l'établissement d'un glossaire du patrimoine culture immatériel, projet de rapport soumis aux participants ci-contre

Siège de l'Unesco à Paris, bâtiment Fontenoy, Salle I.

Des délégués permanents participent à la 35ème Conférence générale de l'Unesco, 2009.

(C) Michel Ravassard/Unesco. 


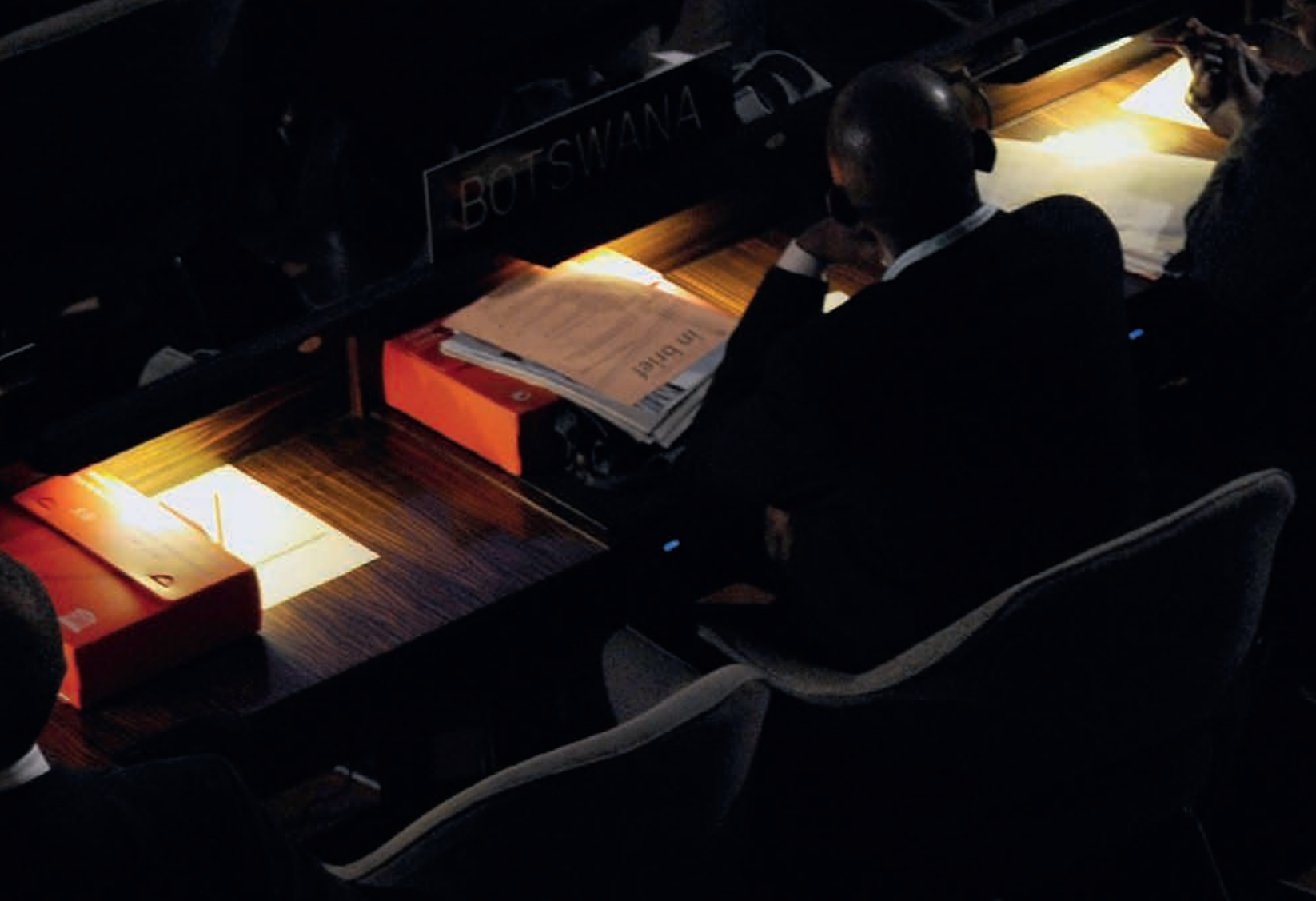

